This item was submitted to Loughborough's Research Repository by the author.

Items in Figshare are protected by copyright, with all rights reserved, unless otherwise indicated.

\title{
Energy storage and its use with wind power
}

PLEASE CITE THE PUBLISHED VERSION

http://dx.doi.org/10.1109/PES.2005.1489154

PUBLISHER

(c) IEEE

VERSION

AM (Accepted Manuscript)

LICENCE

CC BY-NC-ND 4.0

REPOSITORY RECORD

Barton, John P., and David Infield. 2019. "Energy Storage and Its Use with Wind Power". figshare. https://hdl.handle.net/2134/14420. 
This item was submitted to Loughborough's Institutional Repository (https://dspace.lboro.ac.uk/) by the author and is made available under the following Creative Commons Licence conditions.

\section{creative
commons}

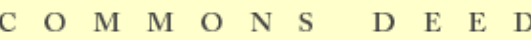

Attribution-NonCommercial-NoDerivs 2.5

You are free:

- to copy, distribute, display, and perform the work

Under the following conditions:

Attribution. You must attribute the work in the manner specified b the author or licensor.

Noncommercial. You may not use this work for commercial purposes.

No Derivative Works. You may not alter, transform, or build upon this work.

- For any reuse or distribution, you must make clear to others the license terms of this work.

- Any of these conditions can be waived if you get permission from the copyright holder.

Your fair use and other rights are in no way affected by the above.

This is a human-readable summary of the Leqal Code (the full license).

\section{Disclaimer 만}

For the full text of this licence, please go to: http://creativecommons.org/licenses/by-nc-nd/2.5/ 


\title{
Energy Storage and its Use with Wind Power
}

\author{
John P. Barton and David G. Infield, Loughborough University, UK
}

\begin{abstract}
A simple probabilistic method has been developed to predict the ability of energy storage to accommodate the intermittency of wind-powered generation. This method can estimate the fraction of time the store is empty or full, the amount of wind energy that must curtailed and the amount of electrical demand left unsatisfied by wind power alone. The method can be applied to stand-alone systems or to weak electricity grids where the level of wind powered generation would be limited by network constraints. A wide range of time scales from seconds to months can be accommodated. The method is briefly outlined, and illustrated by example.
\end{abstract}

Index Terms - Energy storage, Interconnected power systems, Modeling, Power distribution, Wind power generation.

\section{INTRODUCTION}

E NERGY storage for installation within an electricity distribution system can be provided by a range of technologies and can add value in a variety of ways [1]. Income may be derived from an energy store by charging it when the local electricity value is low and discharging it when the value is high. If, at some times, the grid at the point of connection of the wind turbines cannot absorb their entire output, then this generation must be curtailed and the value of the excess is effectively zero. If, at other times, demand is high and expensive generators are used, then the value of electricity will be high. Another source of income results from the supply of ancillary services, for example reactive power, voltage and frequency control and emergency power during a power outage (known as black start). This paper focuses on the first situation, in which the value of a store depends on time variations in the local cost of electricity.

Wind power is currently the fastest growing renewable energy source worldwide. It also poses the most immediate challenges for grid connection and network operation. Wind turbine output depends directly on wind speed and varies across a wide range of time scales.

\section{MODELLING ASSUMPTIONS}

\section{A. Outline of Methodology}

This computational method developed relies upon spectral description of the wind speed together with standard power

J. P. Barton is a PhD student at CREST in the Dept. of Electronic and Electrical Engineering, Loughborough University, LE11 3TU, UK (e-mail: j.p.barton@lboro.ac.uk).

D. G. Infield is Director of CREST and Professor of Renewable Energy Systems within the Department of Electronic and Electrical Engineering, Loughborough University, LE11 3TU, UK curve for the wind turbines, an assumed constant electricity load over time period in question (variable loads can be accommodated but for simplicity have been excluded in this paper), and represents the energy storage system as a series of filters in the spectral domain.

\section{B. Wind Turbine Modeling}

A generic power curve for a $1 \mathrm{MW}$ wind turbine has been used for the calculations presented here, Fig. 1. The curve was constructed from data for commercially available wind turbines [2].

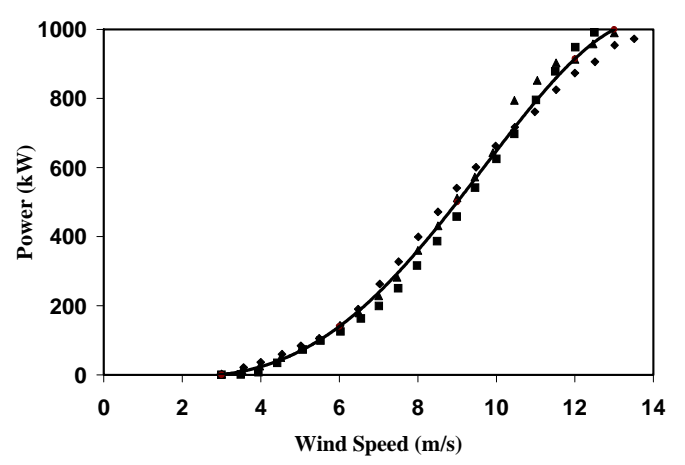

Fig. 1. Composite 1MW Turbine Power Curve From Three Commercial Turbines

\section{Wind Speed Variations}

The Van Der Hoven spectrum [3] describes wind speed variations up to 1000 hours in duration. Corresponding spectra must be calculated from local wind speed data in order to predict accurately the character of wind power variations at a given location. Data has been analyzed for a well-documented location, The Rutherford Appleton Laboratory (RAL) in Oxfordshire, UK Fig. 2.

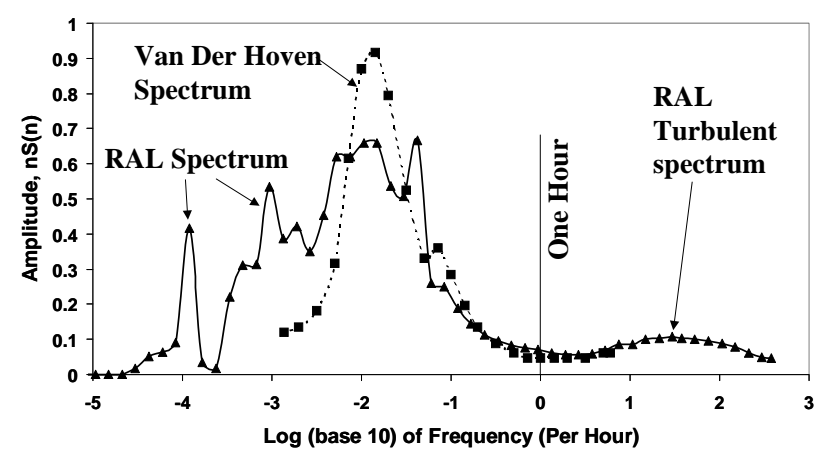

Fig. 2. Wind Speed Variation Spectra Adjusted to $8 \mathrm{~m} / \mathrm{s}$ Mean Wind Speed

Probability density functions for wind speed are commonly taken to be Weibull; the shape and scale 
parameters of which have been identified for the Oxfordshire site.

\section{CALCULATION APPROACH}

\section{A. Spectral Analysis Methods}

Filter functions have been applied to the spectrum of wind speed variations from RAL, Fig. 2, in order to calculate the probability distribution of period-average wind speeds, the distribution of wind speeds within each period, and the size (energy capacity) of the required store. For a given store frequency component, $\omega_{i}$ with amplitude, $A$ and phase angle

$\varphi_{i}$, the instantaneous component of wind speed is: $U_{i}=A_{i} \sin \left(\omega_{i} t+\phi_{i}\right)$.

Averaging this quantity over the store period, $T$ gives the contribution from this frequency to the period-average wind speed:

$$
\overline{U_{i}}=\frac{A_{i}}{\omega_{i} T}\left[\cos \phi_{i}-\cos \left(\omega_{i} T+\phi_{i}\right)\right] .
$$

This average is then squared and integrated over all $\varphi_{i}$ from 0 to $2 \pi$ to give the contribution to the variance in the period average wind speed. The resulting integral is:

$$
V_{1 i}=\left(\frac{A_{i}}{\omega_{i} T}\right)^{2}\left[1-\cos \left(\omega_{i} T\right)\right] \text {. }
$$

This formula is the same as the low pass filter used by Infield [4] for storage modeling, but without the 2.4 empirical scaling factor. The filter for a one-hour store is shown Fig. 3. Low frequency components (small $\omega$ ) have a relatively large effect on the period average wind speed whereas high frequency components (large $\omega$ ) have a small effect on the period average. Low frequency components remain nearly constant throughout a time period, $T$. High frequency components of wind variation complete many cycles during the time, $T$, and time spent above the long-term mean is approximately balanced by time spent below.

The variance of wind speeds within a period, $T$ is calculated in a similar way, but this time, the important quantity is the difference between the instantaneous wind speed, $U_{i}$ and the period-average, $\overline{U_{i}}$ :

$U_{i}-\overline{U_{i}}=A_{i} \sin \left(\omega_{i} t+\phi_{i}\right)-\frac{A_{i}}{\omega_{i} T}\left[\cos \phi_{i}-\cos \left(\omega_{i} T+\phi_{i}\right)\right]$

If this quantity is squared, integrated over time, $T$ and averaged over all possible values of $\varphi_{i}$, then the component of wind speed variance within period $T$ results:

$V_{2 i}=\frac{A_{i}^{2}}{2}-\left(\frac{A_{i}}{\omega_{i} T}\right)^{2}\left[1-\cos \left(\omega_{i} T\right)\right]$

This integral represents a high pass filter, previously derived by Bossanyi [5] and also shown in Fig. 3. It is actually the complement of the low pass filter function in the sense that summing the two time series resulting from application of the two filters to a given time series results in the original series.

A third filter function is used to calculate the variance in state-of-charge of a store associated with a particular frequency component, $\omega_{i}$ :

$$
V_{\text {SOC }}=\frac{A_{i}^{2}}{\omega_{i}^{2}}\left\{\frac{5}{6}+\frac{1}{6} \cos \left(\omega_{i} T\right)+\frac{2}{\omega_{i}^{2} T^{2}}\left[\cos \left(\omega_{i} T\right)-1\right]\right\}
$$

This is applied to the original spectral density. Integration of the resulting spectrum gives the variance of wind speed $\mathrm{x}$ time. This is square-rooted and multiplied by the average gradient from the turbine power curve to produce a standard deviation of state-of-charge. The effective energy capacity of the store is approximately given by twice the standard deviation of state-of-charge. The factor of 2 is empirical (rather like the factor of 2.4 used by Infield) but is intuitively the result of the symmetry about the mean value mentioned above.

Low frequency components have little effect on the store, since their magnitude varies so little during period, $T$. High frequency components also have little effect on the store, since they complete many cycles during period, $T$, so each cycle accumulates and discharges very little energy.

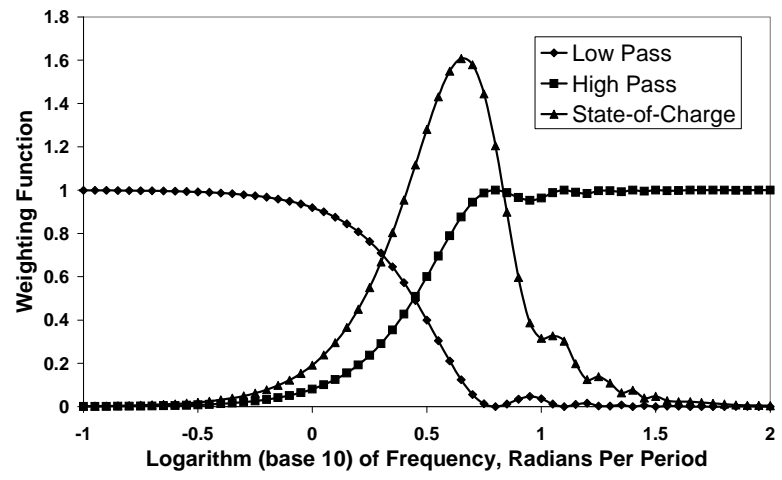

Fig. 3. Spectrum filter functions

\section{B. Wind Speed Distributions}

In the examples given in this paper, all wind speed distributions have been corrected to a long-term mean wind speed of $8 \mathrm{~m} / \mathrm{s}$. At short time scales, e.g. one hour, the wind speed is described by a long-term Weibull distribution of hourly average wind speeds combined with short-term, Gaussian distributions of turbulent wind speeds, about the hourly average. At longer time scales, typically a month, the wind speed is described by a long-term Gaussian distribution of monthly average wind speeds combined with Weibull distributions covering the range minutes to days. The probabilistic method uses either Weibull or Gaussian distributions depending on the size of the variation, predicted by the filter functions.

\section{The Probabilistic Method}

The operation of energy storage has been modelled using probabilities, presented within a matrix describing short-term and long-term wind speed variations. A very simplified 
example of an hourly matrix is shown in Table I. For the example matrix, the long-term average wind speed is $8 \mathrm{~m} / \mathrm{s}$ and the standard deviation of wind speed variation within each hour is 1.95 , representing a turbulence intensity of $24 \%$. This is somewhat larger than the actual turbulence intensity at the RAL site, and is used for illustration only. The distribution of hourly average wind speeds is modelled by a Weibull distribution. Each row represents a different interval of average wind speed over a period (in this example, one hour). Let us call the mid-value of this interval $\mathrm{U}_{1}$. In the example, $\mathrm{U}_{1}$ takes three possible values: $4 \mathrm{~m} / \mathrm{s}$ (representing hourlyaverage wind speeds from $0 \mathrm{~m} / \mathrm{s}$ to $6 \mathrm{~m} / \mathrm{s}$ ); $8 \mathrm{~m} / \mathrm{s}$ (representing hourly-average wind speeds from $6 \mathrm{~m} / \mathrm{s}$ to $10 \mathrm{~m} / \mathrm{s}$ ); and $12 \mathrm{~m} / \mathrm{s}$ (representing hourly-average wind speeds above $10 \mathrm{~m} / \mathrm{s}$ ). Each element within each row represents a different interval of instantaneous wind speed (second by second) higher or lower than $U_{1}$. The instantaneous wind speed $=U_{1}+U_{2}$, where $U_{2}$ is the interval mid-value of the instantaneous variation. The matrix has been constructed so that each column represents a fixed ratio of $\mathrm{U}_{2} / \mathrm{U}_{1}$ (for the case of hourly modelling this represents a fixed value of turbulence intensity as would be expected for a given site). In the example spreadsheet of Table I, $U_{2}$ takes values of $-1,0$ and +1 times the standard deviation of variation within one hour. For example, when the hourly average is $4 \mathrm{~m} / \mathrm{s}, \mathrm{U}_{2}$ takes values of about $-1 \mathrm{~m} / \mathrm{s}, 0 \mathrm{~m} / \mathrm{s}$ and $+1 \mathrm{~m} / \mathrm{s}$, giving absolute wind speeds of $3 \mathrm{~m} / \mathrm{s}, 4 \mathrm{~m} / \mathrm{s}$ and $5 \mathrm{~m} / \mathrm{s}$. These values of $U_{1}+U_{2}$ actually represent ranges of wind speeds: the first column represents values of wind speed less than the mean minus half a standard deviation $\left(\mathrm{U}_{1}+\mathrm{U}_{2}<3.5 \mathrm{~m} / \mathrm{s}\right)$; the middle column represents wind speeds from mean minus half a standard deviation to mean plus a half standard deviation $\left(3.5<\mathrm{U}_{1}+\mathrm{U}_{2}<4.5\right)$; the final column represents wind speeds greater than mean plus half a standard deviation $\left(4.5<\mathrm{U}_{1}+\mathrm{U}_{2}\right)$.

Each element in the matrix is also associated with a wind turbine power output calculated using the turbine power curve of Fig. 1, at a wind speed of $\mathrm{U}_{1}+\mathrm{U}_{2}$, see Table I. For each time scale considered, all variations in wind speed slower than the time scale in question are described by one probability distribution function, $\mathrm{p}\left(\mathrm{U}_{1}\right)$, (one value of probability for each row of the matrix). Variations faster than the time scale are described by a second probability distribution of wind speeds within the time period, $\mathrm{p}\left(\mathrm{U}_{2}\right)$, (one value for each column of the matrix). In the case of a one-hour store, this second distribution describes turbulent variations in wind speed, and is best represented by a Gaussian distribution. The wind speed distributions are described in more detail in section III $B$ below. The wind speed spectrum can be usefully split into two as shown in Fig. 2. To the right of the line, all variation in power output is assumed to be smoothed by the one-hour energy store. To the left of the line the variations cannot be smoothed by the store because of its limited size.

In the spreadsheets, energy can be 'taken' from points with high wind power output and 'given' to other points in the same row with lower power. This represents the action of a store absorbing transient surpluses and delivering this as useful energy a short period later. Energy cannot be exchanged between rows because this would require longerterm energy storage than is being modelled. The precise redistribution is not important and is not calculated, but the spreadsheets do calculate the total amount of power transferred, and the total amount of extra energy exported to the electricity network, see Table I. For the example in question, the chosen maximum charging and discharging power of the store is $300 \mathrm{~kW}$. One particular time of day has been chosen, in which the maximum power that can be absorbed by the local electricity network is $602 \mathrm{~kW}$. Each hourly-average case is now considered:

1) Row 1:

When the hourly average wind speed, $U_{1}$ is $4 \mathrm{~m} / \mathrm{s}$, the wind turbine is only generating for a small proportion of the time. When it does generate, the local network can absorb the entire power. The store would be able to export an additional $300 \mathrm{~kW}$ (limited by the power rating of the store) but this power is just not available. In this case, the store does not increase the power exported.

\section{2) Row 2:}

When the hourly average wind speed, $\mathrm{U}_{1}$ is $8 \mathrm{~m} / \mathrm{s}$, there are occasions when the wind power exceeds $602 \mathrm{~kW}$ (by $39 \mathrm{~kW}$ when $U_{1}+U_{2}$ is $\left.10 \mathrm{~m} / \mathrm{s}\right)$. The probability-weighted average excess power is $12 \mathrm{~kW}$, but the store has a finite round-trip efficiency of $90 \%$, so the power available is only $11 \mathrm{~kW}$. The store would be able to export an additional $185 \mathrm{~kW}$ on average (sometimes limited by the network capacity and sometimes by the store discharge power rating of $300 \mathrm{~kW})$. However, the extra exported energy is limited by the former quantity, the available stored power. Therefore the extra exported energy is only $11 \mathrm{~kW}$.

3) Row 3:

When the hourly average wind speed, $U_{1}$ is $12 \mathrm{~m} / \mathrm{s}$, the wind power exceeds the local Network capacity most of the time. The wind power exceeds the limit of $602 \mathrm{~kW}$ by $243 \mathrm{~kW}$ on average. The average excess power that the store could absorb is then $207 \mathrm{~kW}$, limited by the store maximum charging rate of $300 \mathrm{~kW}$. When multiplied by the store efficiency of $90 \%$, this becomes $186 \mathrm{~kW}$. However, on this occasion, the power that the store can export is limited by the local network capacity. The average extra exported power is therefore only $28 \mathrm{~kW}$.

Of course, the actual matrix includes many more values of $\mathrm{U}_{1}$ (rows) and $\mathrm{U}_{2}$ (columns) to achieve a representative model, and also take into account the round trip efficiency of the energy storage technology being considered. The one-hour storage matrix assumes an efficiency of $90 \%$ appropriate to a high-speed flywheel system. 
TABLE I

ILLUSTRATION OF AN HOURLY SPREADSHEET METHOD

\begin{tabular}{|c|c|c|c|c|}
\hline $\begin{array}{l}\text { Wind Turbine Power } \\
\text { Capacity }=1000 \mathrm{~kW}\end{array}$ & $\begin{array}{l}\text { Mean } \\
-1 \\
\text { Std. } \\
\text { Dev. }\end{array}$ & Mean & $\begin{array}{l}\text { Mean + } \\
1 \text { Std. } \\
\text { Dev. }\end{array}$ & $\begin{array}{l}\text { Probability } \\
\text { Weighted } \\
\text { Average }\end{array}$ \\
\hline Probabilities & 0.31 & 0.38 & 0.31 & \\
\hline \multicolumn{5}{|l|}{$\begin{array}{l}\text { Row 1: } U_{1}=4 \mathrm{~m} / \mathrm{s}, \\
\text { Probability }=0.43\end{array}$} \\
\hline $\mathrm{U}_{1}+\mathrm{U}_{2}$ & 3.0 & 4.0 & 5.0 & 4.0 \\
\hline Wind Power, kW & 0 & 24 & 67 & 30 \\
\hline Excess Power, kW & 0 & 0 & 0 & 0 \\
\hline Power Stored, kW & 0 & 0 & 0 & 0 \\
\hline $\begin{array}{l}\text { Extra Discharge } \\
\text { Capacity, kW }\end{array}$ & & 300 & 300 & 300 \\
\hline $\begin{array}{l}\text { Extra Power to } \\
\text { Network, kW }\end{array}$ & & & & 0 \\
\hline \multicolumn{5}{|l|}{$\begin{array}{l}\text { Row } 2: \mathrm{U}_{1}=8 \mathrm{~m} / \mathrm{s}, \\
\text { Probability }=0.36\end{array}$} \\
\hline $\mathrm{U} 1+\mathrm{U} 2$ & 6.0 & 8.0 & 10.0 & 8.0 \\
\hline Wind Power, kW & 144 & 360 & 641 & 380 \\
\hline Excess Power, kW & 0 & 0 & 39 & 12 \\
\hline Power Stored, kW & 0 & 0 & 39 & 12 \\
\hline $\begin{array}{l}\text { Extra Discharge } \\
\text { Capacity, kW }\end{array}$ & 300 & 241 & 0 & 185 \\
\hline $\begin{array}{l}\text { Extra Power to } \\
\text { Network, kW }\end{array}$ & & & & 11 \\
\hline \multicolumn{5}{|l|}{$\begin{array}{l}\text { Row 3: U1=12m/s, } \\
\text { Probability }=0.21\end{array}$} \\
\hline $\mathrm{U}_{1}+\mathrm{U}_{2}$ & 9.1 & 12.0 & 14.9 & 12.0 \\
\hline Wind Power, kW & 510 & 915 & 1000 & 816 \\
\hline Excess Power, kW & 0 & 313 & 398 & 243 \\
\hline Power Stored, kW & 0 & 300 & 300 & 207 \\
\hline $\begin{array}{l}\text { Extra Discharge } \\
\text { Capacity, kW }\end{array}$ & 92 & 0 & 0 & 28 \\
\hline $\begin{array}{l}\text { Extra Power to } \\
\text { Network, kW }\end{array}$ & & & & 28 \\
\hline
\end{tabular}

\section{F. Energy Rating Calculations}

The probabilistic matrix method outlined above approximates the temporal aspects of operation: when and how often the store fills and empties, and hence it can predict the required energy rating of the store, and the fractions of time that the store is full or empty.

To illustrate the calculation approach some example results are presented in section IV below. These calculations have also been validated against more conventional time step modeling. The results have been calculated for a store where the long-term average wind power is almost equal to the longterm average demand, where the efficiency of the store is $100 \%$ (no losses) and where the charging and discharging rates of the store are unrestricted.

\section{RESULTS}

The state-of-charge filter function has been applied to the RAL spectrum and gives the predicted store sizes for each period length, Fig. 4. These store sizes have been used in the time-step simulations used to verify the probabilistic method.

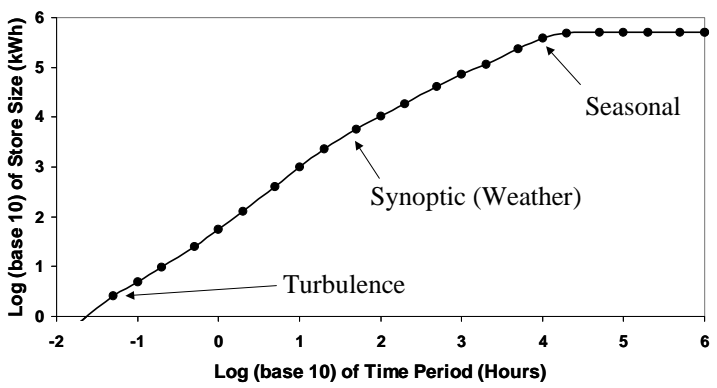

Fig. 4. Calculated store size vs. time scale

The probabilistic method predicts the electrical demand left unsatisfied by wind power and the store as shown in Fig. 5. Because in this example the average wind power almost balances the electricity demand, the unsatisfied demand is almost equal to the curtailed wind power.

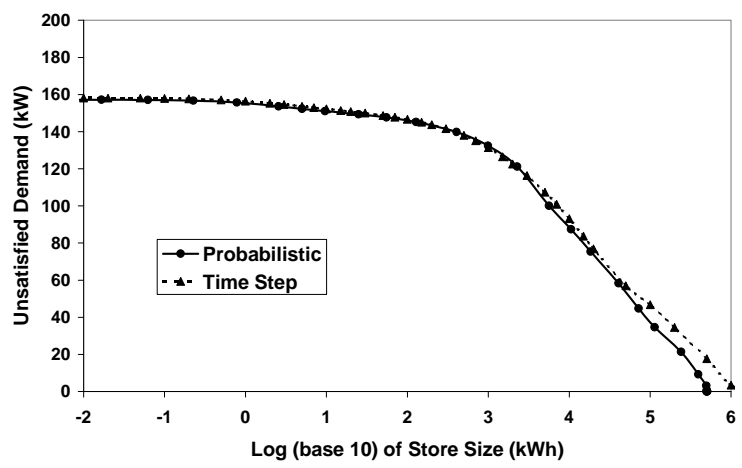

Fig. 5. Electrical demand left unsatisfied by wind power vs. store size

The method can also predict the power throughput, that is the average power either entering or leaving the store, Fig. 6.

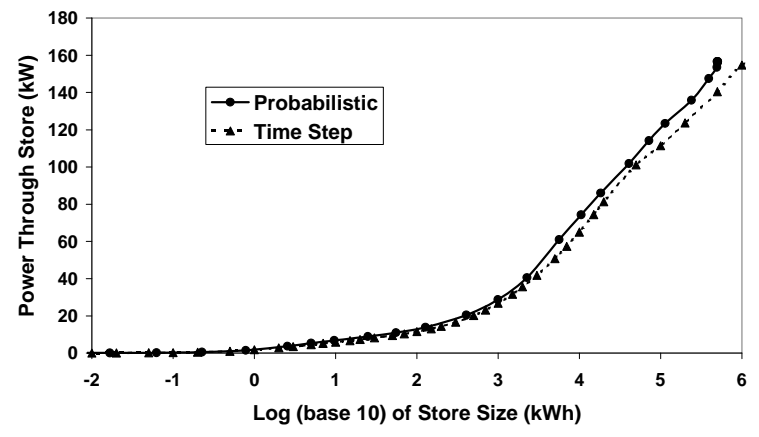

Fig. 6. Average power entering and leaving the store

Fig. 7 shows calculations of the fractions of time that the store is empty and full. 


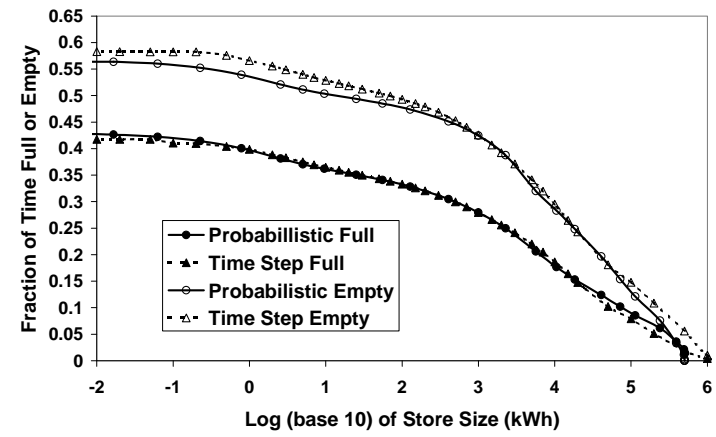

Fig. 7. Fractions of time that the store is full or empty

\section{CONCLUSIONS}

The research presented here has demonstrated that key aspects of the use of energy storage to improve wind power integration can be captured by a simplified probabilistic approach. This has the distinct advantage over conventional time step numerical modeling of requiring only limited input data, and reducing computational effort. Specific conclusions based on the modeled example indicate that: -

1. Energy storage over 10 minutes, using for example, flywheels, could allow $10 \%$ more wind energy to be absorbed without grid reinforcement, and appears in this particular case to be economically worthwhile given reasonable storage cost assumptions.

2. Energy storage over 24 hours using perhaps redox flow cells would allow up to $25 \%$ more wind energy to be absorbed and $30 \%$ more revenue to be earned. With the current costs of such flow cells, this would appear to be uneconomic.

3. Even energy storage capacity up to 1 day cannot exclude the possibility of energy curtailment for a weak grid connection.

4. Energy management, combining energy storage over 24 hours with energy curtailment, can allow up to 3 times the amount of wind energy to be absorbed by a weak grid.

\section{ACKNOWLEDGEMENTS}

The authors of this paper would like to express their gratitude and sincere appreciation to Mr. Richard Cooke of Alstom, and Dr. Simon Watson and Mr. Murray Thompson of CREST for their valuable comments and suggestions. We would also like to thank the British Atmospheric Data Centre for supplying wind speed data.

\section{REFERENCES}

[1] J.P. Barton and D.G. Infield, "Energy storage and its use with intermittent renewable energy", IEEE Trans.Energy Convers., 19(2), pp. 441-448, June 2004.

[2] "Windenergie 2000" turbine catalogue, Bundesverband WindEnergie e.V., 2000, ISBN 3-9806657-2-0

[3] U. Hassan and D. M. Sykes, "Wind Structure and Statistics", in Wind Energy Conversion Systems chapter 2, L. L. Freris, Ed. UK: Prentice Hall, 1990, pp. 11-32.
[4] D.G. Infield, “Storage and Logistics”, in Wind Energy Conversion Systems chapter 16, L. L. Freris, Ed. UK: Prentice Hall, 1990, pp. 341-356.

[5] E.A. Bossanyi, "Comparison of Techniques for Evaluating the Frequency of Wind Turbine Shut-Downs", Proceedings of the $6^{\text {th }}$ BWEA Wind Energy Conference, 1984, UK: Cambridge Univ. Press, pp. 228-238

John P. Barton was born in Nottingham, England on $20^{\text {th }}$ September 1966. He received the B.A. and M.A. degrees in Mechanical Engineering from Cambridge University in 1989 and 1993.

He worked on the design of gas turbine compressors and fans at RollsRoyce plc. before receiving the MSc. in Renewable Energy Systems Technology from Loughborough in 2001. He is now studying for a $\mathrm{PhD}$ at Loughborough University. His area of interest is the use of energy storage with renewable energy sources in electricity networks.

David G. Infield was born in Paris on the $30^{\text {th }}$ March 1954 . He was brought up and educated in England, gaining a BA in Mathematics and Physics from the University of Lancaster and a PhD in Applied Mathematics from the University of Kent at Canterbury. He worked first for the Building Services Research and Information Association, Bracknell, UK, on solar thermal system design, and then for the Rutherford Appleton Laboratory, from 1982 to 1983, on wind energy systems and electricity supply modeling. He is currently Director of CREST (Centre for Renewable Energy Systems Technology) and Professor of Renewable Energy Systems with the Department of Electronic and Electrical Engineering at Loughborough University, UK. He is a member of the IEEE. 